\title{
Potential trophic importance of the faecal material of the mangrove sesarmine crab Sesarma messa
}

\author{
S. Y. Lee* \\ The Swire Institute of Marine Science, and Department of Ecology \& Biodiversity, The University of Hong Kong, \\ Pokfulam Road, Hong Kong
}

\begin{abstract}
The potential trophic importance of the sesarmine crab Sesarma messa Campbell in a northeastern Australian mangrove dominated by Rhizophora stylosa Griff. was evaluated by quantifying the rates of mangrove leaf litter consumption, the corresponding faecal production and assimilation efficiency of mangrove organic matter by the crab. S. messa seems to remove primarily carbon rather than nitrogen from the mangrove litter, as is reflected by the decrease in C but slight increase in $\mathrm{N}$ content of the faeces over mangrove litter. Assimilation efficiency for mangrove organic matter was only at about $50 \%$. The potential significance of the crab faecal material in initiating a coprophagous food chain involving mangrove invertebrates was assessed by a series of growth experiments using the hyalid amphipod Parhyalella sp., which is commonly (mean density of 204 ind. $1^{-1}$ of detritus) found amongst accumulated detritus near the mangrove forest. Parhyalella sp. individuals fed with crab faecal material or a mixture of faecal material and mangrove detritus attained significantly higher moulting frequency but lower mortality rates than their counterparts in the mangrove detritus only treatment and the control (no food) over a period of $26 \mathrm{~d}$, although \% gut fullness was not significantly different amongst the 3 diet treatments. Assimilation of crab faecal material by Parhyalella sp. was almost complete, while individuals fed with $R$. stylosa litter could assimilate only about $51 \%$ of the organic matter in their diet. Decomposition of crab faecal material resulted in a significant increase in $\mathrm{N}$ but decrease in $\mathrm{C}$ content over $24 \mathrm{~d}$. The $\mathrm{C} / \mathrm{N}$ ratio of the faecal material was significantly lower than that of the mangrove litter from which it was generated and decreased linearly with time of decomposition. S. messa therefore are not only important as a significant agent effecting fast recycling of mangrove leaf litter, but their faeces, from leaf litter consumption, may also form the basis of a coprophagous food chain contributing to mangrove secondary production by small invertebrates such as Parhyalella sp.
\end{abstract}

KEY WORDS: Coprophagy Mangrove leaf litter Sesarmine crabs Amphipod Assimilation efficiency

\section{INTRODUCTION}

One major finding of the ecological and taxonomic investigations conducted in Indo-West-Pacific mangrove ecosystems in the past decade is the profound importance of crabs, mostly of the sub-family Sesarminae, to the structure and function of the mangroves. The sesarmines attain extreme diversity and richness

\footnotetext{
- Present address: School of Applied Science, Griffith University Gold Coast, PMB 50 Gold Coast Mail Centre, Queensland 9726, Australia.E-mail: joe.lee@gu.edu.au
}

in the Indo-Pacific mangroves. The account by Jones (1984), which must now be considered grossly outdated, first discussed the taxonomic diversity and potential ecological importance of brachyuran crabs in mangrove ecosystems. More recent works have pointed to much higher taxonomic diversity and confirmed the ecological significance of crabs, in especially in the Indo-Pacific mangroves. For example, Tan \& Ng (1994) reported the accurrence of 44 species of sesarmines belonging to 16 genera from the mangroves of peninsular Malaysia and Singapore, while Davie (1994) recorded from 5 to 19 grapsid, mostly sesarmine, species from mangroves in tropical Aus- 
tralia. S. Y. Lee, A. Dai \& Y. Car (unpubl.) described 25 species of sesarmines from Hong Kong, most of which are mangrove-associated. It appears that crab diversity may be positively correlated with mangrove diversity (Kwok 1995), but confirmation of such a relationship still awaits further comprehensive surveys of mangrove crab assemblages over wider latitudinal gradients. While it is conceivable that, in view of the intense interaction between the 2 groups, mangrove diversity may be positively correlated with crab diversity, local factors such as the amount of precipitation may confound this relationship (e.g. Davie 1994).

In addition to high taxonomic diversity, the abundance of sesarmine crabs also adds to their ecological importance in the Indo-Pacific mangrove ecosystems. While a reliable method for estimating crab density in mangroves has yet to be devised, surveys using pitfall traps (e.g. Smith et al. 1991) and visual counts (e.g. Kwok 1995) suggest high abundances throughout the Indo-Pacific mangroves.

The importance of sesarmine crabs to mangrove community structure and function was first hinted at by the observation of Macnae (1968) that heavy mortality on mangrove seedlings often results from sesarmine crab attacks on plantations. In the last decade, however, a large volume of data has accumulated to demonstrate the actual importance of the sesarmines in Indo-Pacific mangroves. Thus, Robertson (1986) and Giddens et al. (1986) first documented that the removal of fresh mangrove leaf litter by sesarmines had the effect of significantly reducing tidal export. This previously unrecognised process is actually often the most important fate of mangrove leaf litter, dominating over the better known processes of microbial decay and tidal export in many mangrove forest types in tropical Australia (Robertson 1991). The role of the sesarmines as a prime agent in processing mangrove leaf litter has been confirmed by more recent field and laboratory studies conducted in Hong Kong (Lee 1989, Kwok \& Lee 1995), northern Queensland (Robertson \& Daniel 1989, Micheli 1993a, b), Thailand (Poovachiranon \& Tantichodok 1991) and South Africa (Emmerson \& McGwynne 1992. Steinke et al. 1993)

Through their burrowing and feeding activities, the sesarmines also influence mangrove community structure. Smith (1987a, b, 1988) documented significant but differential predation of mangrove propagules by sesarmine crabs in northern Australia. Differential predation on different species, often also varying according to different degrees of tree dominance, makes the crabs a significant agent in the shaping of mangrove community structure. This interaction involving the sesarmines seems to be of particular importance in the Indo-Pacific mangroves as compared to the Caribbean system (Smith et al. 1989, McIvor \& Smith 1995), where sesarmine diversity and abundance are considerably lower (see Abele 1992, $\mathrm{Tan} \& \mathrm{Ng} 1994$ ).

Sesarmine crabs are also capable of influencing mangrove system dynamics by altering the physical environment through their burrowing activities. Warren \& Underwood (1986) reported changes in surface topography as well as sediment particle size distribution in a New South Wales mangrove following crab bioturbation. Smith et al. (1991) documented significant differences in sediment sulphide and ammonium concentrations between crab-excluded and control areas, which resulted in growth and productivity differences of the mangroves. These studies, along with similar studies conducted in salt marsh systems (e.g. Bertness 1985, Taylor \& Allanson 1993), reiterate the importance of crabs in the structure and function of coastal wetland ecosystems, the actual magnitude of the influence being dependent on the level of abundance and diversity of the crabs.

Although the role of sesarmine crabs as an agent effecting mangrove leaf litter turnover in the IndoPacific is indisputable, the exact trophic importance of this link in the mangrove food chain has yet to be ascertained. What happens to the organic matter and nutrients consumed by the crabs through their processing of mangrove leaf litter? This report investigates (1) the form and quantity of faecal material produced by the common northeastern Australian sesarmine crab Sesarma messa Campell through mangrove Rhizophora stylosa Griff, leaf litter consumption and (2) the value of crab faecal material to other invertebrates in the mangrove detritus food chain. This information will further help in the evaluation of the trophic importance of the leaf-litter-consuming sesarmine crabs in the Indo-Pacific mangroves.

\section{MATERIALS AND METHODS}

Study site and organisms. Individuals of the sesarmine crab Sesarma (Perisesarma) messa were collected from a mixed Rhizophora stylosa-Avicennia marina-Ceriops tagal forest in Chunda Bay $\left(19^{\circ} 17^{\prime} \mathrm{S}\right.$ $\left.147^{\circ} 3^{\prime} E\right)$ near the Australian Institute of Marine Science at Cape Ferguson, northeastern Australia. The forest is dominated by $R$. stylosa, near which $S$. messa can be commonly found burrowing in the sandy mud Leaf litter of $R$. stylosa for the laboratory experiments was also collected from the same site.

The amphipod Parhyalella sp. inhabits the littoral and intertidal fringe of Chunda Bay, where large quantities of detritus, mainly of mangrove origin, accumulate. The detritus pool where Parhyalella sp. occurs is situated at $<200 \mathrm{~m}$ from the mangroves towards the 
bottom of Chunda Bay. Due to the proximity of the detritus accumulation to the mangroves and also the high abundance (see below) of the amphipod, Parhyalella was selected as an invertebrate species which may represent a link with the litter-consuming sesarmine crabs through the process of coprophagy.

Abundance of the amphipod. Since Parhyalella sp. inhabits a 3-dimensional matrix of detritus particles, abundance was assessed on a volume basis. Density of Parhyalella sp. in the detritus pool was estimated by collection of 10 random $1 \mathrm{l}$ samples of detritus during low tide. Amphipods in the detritus samples were then killed by brief immersion of the volume of detritus in hot water. This treatment immobilised the amphipods and allowed easy and accurate sorting. The amphipods were then hand-picked from the detritus, counted and dried at $70^{\circ} \mathrm{C}$ for $48 \mathrm{~h}$ for biomass measurement. From the samples collected, Parhyalella sp. attained a high density of $203.7 \pm 107.6$ ind. $1^{-1}$ (mean $\pm 1 \mathrm{SD}$ ) and dry biomass of $0.051 \pm 0.027 \mathrm{~g} \mathrm{l}^{-1}$ of detritus in Chunda Bay.

Leaf consumption and faecal production by Sesarma messa. In order to assess the importance of a potential coprophagous food chain based on the leaf consumption activities of $S$. messa in the mangrove, leaf consumption rate by the crab was measured in the laboratory. Twenty-five individuals of $S$. messa of carapace width (CW) from 12 to $25 \mathrm{~mm}$ were collected from Chunda Bay by hand and kept separately in shaded containers with $5 \mathrm{~mm}$ of water. After acclimatisation for $2 \mathrm{~d}$, the crabs were starved for $24 \mathrm{~h}$ and allowed to clear their guts before the start of the consumption experiment. The crabs were then each offered half of a Rhizophora stylosa leaf and allowed to feed on the leaf for $48 \mathrm{~h}$. Leaves used in the experiment were freshly collected from the mangrove forest floor at Chunda Bay. Before the experiment, the leaves were each split along the mid-rib into 2 half leaves. The area of the individual half leaves was measured using a LI-COR leaf area meter to $0.01 \mathrm{~cm}^{2}$ resolution. One of the half leaves was then given to the crabs while the other was immersed in $5 \mathrm{~mm}$ of seawater to provide a control for weight loss due to leaching. The remains of the half leaves fed to the crabs as well as the control leaves were collected after $48 \mathrm{~h}$ and dried at $70^{\circ} \mathrm{C}$ for $48 \mathrm{~h}$ to give the final dry weight. The original dry weight of the leaves was estimated using a regression relationship (forced through the origin) established using a large sample of $R$. stylosa leaves. As the leaf area/dry weight ratio is likely to be less variable than the fresh weight/dry weight ratio, this approach should provide a more accurate measurement of leaf consumption than previous studies employing the latter conversion factor (e.g. Poovachiranon \& Tantichodok 1991 , Micheli 1993a). Leaf consumption rate was estimated in terms of $\mathrm{g}$ dry weight of leaf consumed per $\mathrm{g}$ dry weight of crab per day, by dividing the $48 \mathrm{~h}$ consumption rate by 2 . Dry weight of the crabs was obtained by drying the animals at $70^{\circ} \mathrm{C}$ for $48 \mathrm{~h}$. Since many previous studies calculated consumption rate based on fresh weight of the crabs, the fresh weight/dry weight ratio of the crabs was also estimated.

The faecal production rate of Sesarma messa was estimated in conjunction with the leaf consumption experiment. Faecal pellets were picked from the containers $24 \mathrm{~h}$ after the experiment began and also at the end of the $48 \mathrm{~h}$ period. The faecal material was then dried at $70^{\circ} \mathrm{C}$ for $48 \mathrm{~h}$ to obtain the dry weight. In order to measure the amount of faeces produced per unit weight of food consumed, faeces were collected from the containers $24 \mathrm{~h}$ after the end of the consumption experiment. The total amount of faecal material produced during the $72 \mathrm{~h}$ period is taken to be the total faecal production arising from the amount of leaf litter consumed by the crabs. In order to accurately measure consumption rate and faecal production by small crabs ( $\mathrm{CW}<15 \mathrm{~mm}$ ), a period of $72 \mathrm{~h}$ was allowed before the leaf remains were collected and dried in these cases. As with leaf consumption, faecal production was expressed as $g$ dry $w_{t} \mathrm{~g}^{-1}$ crab dry $w \mathrm{t} \mathrm{d}^{-1}$

Assimilation of mangrove leaves by Sesarma messa was assessed by comparing the chemical composition of the faecal material with that of the diet. Faecal pellets were collected from the containers daily and dried at $70^{\circ} \mathrm{C}$ before being analysed for their carbon and nitrogen content using a Perkin Elmer 2400 autoanalyser. The organic content of the faecal material was measured by combustion at $500^{\circ} \mathrm{C}$ for $3 \mathrm{~h}$. Assimilation efficiency $(A E)$ was estimated by the method of Conover (1966):

$$
A E=\frac{F-E}{(1-E) \bar{F}}
$$

where $F$ is the ash-free dry wt/dry wt ratio in the food and $E$ is the same quantity for the faeces. The concentration of soluble tannins in the leaf litter food and in crab faeces was measured according to the method of Allen (1989).

Chemical change of crab faecal material with time. Faecal pellets were collected every day over a period of $24 \mathrm{~d}$ from a pool of 25 crabs of various sizes fed on fresh Rhizophora stylosa leaf litter. The faecal material was stored in a clean plastic vial in seawater and was allowed to stand at ambient temperature for 2 to $24 \mathrm{~d}$, after which time the faecal material was dried at $70^{\circ} \mathrm{C}$ for later analysis. Changes in the concentration of $\mathrm{N}$ and $C$ of the faecal material with time of decomposition were measured using a Perkin-Elmer 2400 CHN autoanalyser. The corresponding $\mathrm{C} / \mathrm{N}$ ratio of the material was also calculated. 
Coprophagy by Parhyalella sp. on faecal material from Sesarma messa. The value of the faecal material of S. messa to the amphipod Parhyalella sp. was assessed by a laboratory growth experiment. Individuals of Parhyalella sp. were collected from the detritus pool in Chunda Bay. The initial body length of the amphipods was measured using an eye-piece graticule under $12 \times$ magnification. The amphipods were then divided into 4 groups of 30 individuals each, with each group to be subjected to a different dietary treatment (see below). The length distribution of the amphipods was matched amongst the 4 treatments such that the initial body length of the 4 groups was almost identical ( 1 -way ANOVA, $\left.F_{3,116}=0.206, p=0.892, n s\right)$. Since cannibalism, especially during moulting, could be an important mortality factor, each amphipod was kept separately in a small plastic vial with about $5 \mathrm{ml}$ of seawater during the experiment, and growth and mortality were monitored individually.

Growth and survivorship of the amphipods were followed over $4 \mathrm{wk}$. The following diets were given to the 4 groups: (1) Rhizophora stylosa leaf litter only (the R treatment); (2) faecal pellets only, the faecal material being produced by Sesarma messa fed on a $R$. stylosa leaf diet (the $F$ treatment); (3) a mixture of $R$. stylosa leaf litter and faecal pellets from $S$. messa (the RF treatment); and (4) a control group with no food given (the C treatment).

The amphipods were given a partial water change everyday and a complete change once every 3 d. Food was replenished every day according to the treatment and was always given ad libitum to the amphipods. Crab faecal material for the $F$ and RF treatments was obtained from about 20 Sesarma messa individuals kept in containers and fed with only $R$. stylosa litter. Only fresh faecal material from the crabs was used in the experiment, as it is supposed that faecal material from the crabs would not remain intact for more than a couple of tidal cycles in the natural habitat. Amphipods in the $R$ and RF treatments received leaf discs of $6 \mathrm{~mm}$ diameter prepared from leaf litter of $R$. stylosa using a paper hole puncher. The litter given to the amphipods was in a decomposition stage similar to that present in the natural habitat of the amphipods.

The amphipods were kept under ambient temperature and light regimes, but were sheltered from direct sunlight by a plastic mesh. Survival of the amphipods was checked every morning, as was the presence of moults. The body length of the amphipods was measured once every week, and the degree of gut fullness (on a 10\% interval scale) was scored 3 times (at 13, 20 and $28 \mathrm{~d}$ after the start of the experiment) under the microscope. The length and dry weight of the dead individuals were recorded. The experiment was terminated after $25 \mathrm{~d}$, at which time all of the individuals in the con- trol set had died and only 2 in the $R$ set remained. The final body length of all amphipods was recorded and the dry weight measured to $0.01 \mathrm{mg}$ after drying for $48 \mathrm{~h}$ at $70^{\circ} \mathrm{C}$. The weight and body length data were later found to be variable, due to the difficulty in obtaining reliable measurements of body weight in the $0.01 \mathrm{mg}$ region and the fact that movement of the animals precluded accurate measurement of body length. These data were therefore later discarded. Gut fullness, however, could be accurately estimated. Gut fullness was separately compared for data collected on different dates using a Kruskal-Wallis non-parametric ANOVA followed by Dunn's multiple comparison test (more than 2 groups) or a Mann-Whitney test ( 2 groups).

The cumulative moulting frequency and mortality data from the 4 treatment groups were compared using regression analysis and analysis of co-variance (ANCOVA). Regression equations relating cumulative mortality or moulting frequency with time of experiment in days were generated separately for the 4 treatments. The slope of the regression equations, i.e. the number of mortalities/moults per day over the entire experimental period, was then compared for homogeneity by the method of Zar (1984) and followed by the Tukey's multiple comparison test if heterogeneity was detected.

Assimilation efficiency of the different foods by the amphipods was assessed by analysing the chemical composition of their faecal material and compared with that of their food. The amphipods produced small but well formed faecal pellets. The pellets from animals in the various treatments were collected by a Pasteur pipette and then purified first by hand-picking using a pipette under a stereomicroscope. Further purification of the faecal material was achieved by repeated suspension of the mixture of pellets and other debris in a tall but narrow plastic vial and pipetting out the lighter debris from the surface layers of the water. Microscopic examination of the material so collected suggested that an almost pure collection of amphipod faecal pellets could be achieved with repeated resuspension and pipetting. The purified pellets were then dried at $70^{\circ} \mathrm{C}$ before analysis of their nutrient contents ( $\mathrm{C}, \mathrm{H}$ and $\mathrm{N}$ contents by a Perkin Elmer 2400 autoanalyser; organic content by weight loss on ignition at $500^{\circ} \mathrm{C}$ for $3 \mathrm{~h}$ ). Assimilation efficiency was calculated using the method of Conover (1966).

\section{RESULTS}

\section{Consumption and defaecation rate by Sesarma messa}

Leaf laminar area was a reliable predictor of leaf dry weight for Rhizophora stylosa [linear regression equa- 
tion: $g$ dry wt $=0.02647 \times\left(\right.$ leaf area in $\left.\mathrm{cm}^{2}\right), \mathrm{n}=70, \mathrm{r}^{2}=$ $0.987, p<0.0001]$. Both the percentage of carbon and nitrogen in $R$. stylosa leaf litter on the forest floor increased significantly over those in senescent, readyto-fall leaves still attached to the trees (Table 1), but the relative magnitudes of the increases still resulted in a lower $\mathrm{C} / \mathrm{N}$ ratio in the floor litter. The fresh weight/dry weight ratio for $S$. messa was determined to be 3.56 .

Sesarma messa readily consumed fresh leaf litter of Rhizophora stylosa in the laboratory. Consumption rate, after adjusting for leaching loss, averaged at $87.57 \pm 45.31$ (mean $\pm 1 \mathrm{SD}$ ) $\mathrm{mg}$ leaf dry $w \mathrm{t}^{-1} \mathrm{crab}$ dry wt $\mathrm{d}^{-1}$ or $24.60 \pm 12.73 \mathrm{mg}$ leaf dry wt $\mathrm{g}^{-1} \mathrm{crab}$ fresh wt $d^{-1}$. The ratio of the dry weight of leaf consumed to that of faecal material produced during the same $48 \mathrm{~h}$ period averaged $0.684 \pm 0.229$, based on an average faecal production rate of $60.73 \pm 36.33 \mathrm{mg}$ dry wt $\mathrm{g}^{-1}$ crab dry wt $\mathrm{d}^{-1}$.

Assimilation efficiency of the crabs on the Rhizophora stylosa diet was low $150.6 \%$ for organic matter). Sesarma messa seems to utilise significantly the carbon but not the nitrogen in $R$. stylosa leaf litter, as there is a considerable drop in carbon but increase in nitrogen concentration between the leaf litter and crab faeces (Table 1). The $\mathrm{C} / \mathrm{N}$ ratio of the faecal material was much lower than that of $R$. stylosa leaves on the forest floor (48.6 vs 75.0 respectively). The composition of crab faecal material from crabs freshly collected from the mangrove forest differed significantly with that produced by crabs from a pure diet of $R$. stylosa leaves in the laboratory. Percentage carbon was low but nitrogen content was very high $(27.2 \pm 0.9 \%$ and $1.4 \pm 0.1 \%$, respectively), suggesting that the crabs probably had a more diverse, and generally more nitrogen rich, diet than just fresh $R$. stylosa leaf litter.

The tannin concentration of fresh Rhizophora stylosa leaf litter was high, averaging $13.3 \%$ in terms of dry weight. Tannin concentration of crab faecal material was much lower, generally $<3 \%$.

\section{Chemical change of crab faecal material with time}

Despite some fluctuations, the carbon and organic matter contents of crab faecal material decreased significantly with time of decomposition in water while the nitrogen content increased dramatically with prolonged decomposition, i.e. after about 2 wk (Fig. 1). There were wide fluctuations in $\%$ carbon and organic matter of the faecal material in the first $10 \mathrm{~d}$, with
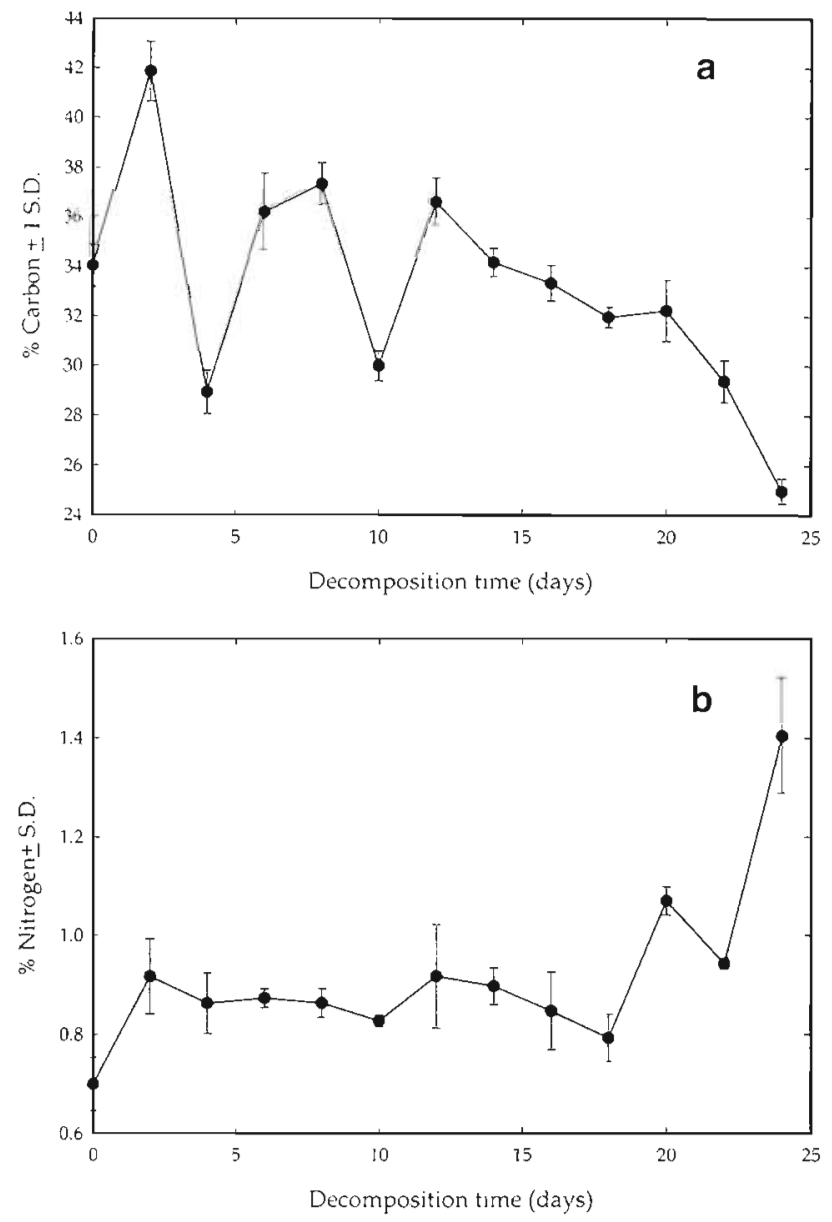

Fig. 1. Change over time in (a) carbon and (b) nitrogen content of faecal material produced by Sesarma messa fed on a Rhizophora stylosa leaf litter diet

values varying between 42 and $29 \%$ and between 59 and $70 \%$ for carbon and organic matter, respectively. Decreasing trends were, however, more noticeable after Day 11, and values steadily declined to about $25 \%$ by Day 24 for carbon and to $50 \%$ for organic matter on Day 26. Changes in \% nitrogen followed an opposite trajectory, with abrupt increases to about

Table 1. Chemical composition of the food and the resulting faecal material of Sesarma messa. Values given are mean $\pm 1 \mathrm{SD}$. OM: organic matter Faecal material was taken from freshly collected crabs (field diet) or crabs fed in the laboratory (Rhizophora stylosa litter)

\begin{tabular}{|lcccc|}
\hline Sample & $\% \mathrm{C}$ & $\% \mathrm{~N}$ & $\mathrm{C} / \mathrm{N}$ & $\% \mathrm{OM}$ \\
\hline Rhizophora stylosa leaf litter & $41.8 \pm 0.6$ & $0.56 \pm 0.09$ & 75.0 & $82.8 \pm 0.20$ \\
Ready-to-fall $R$. stylosa leaves & $39.3 \pm 0.4$ & $0.47 \pm 0.06$ & 83.0 & $77.3 \pm 0.35$ \\
Faeces, field diet & $27.2 \pm 0.9$ & $1.44 \pm 0.11$ & 18.9 & 37.6 \\
Faeces, R. stylosa litter & $34.0 \pm 0.9$ & $0.70 \pm 0.05$ & 48.6 & $70.7 \pm 0.44$ \\
\hline
\end{tabular}




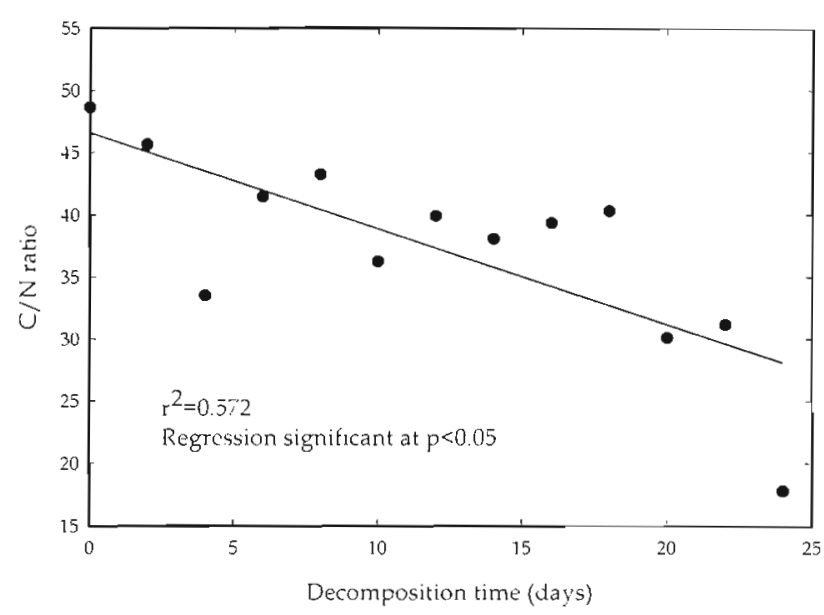

Fig. 2. Change in the $\mathrm{C} / \mathrm{N}$ ratio of decomposing faecal material of Sesarma messa fed on a Rhizophora stylosa leaf litter diet. The ratio decreased linearly with time of decomposition

$1.5 \%$ on Day 24 from a constant level of about $0.9 \%$ in the first $18 \mathrm{~d}$ of decomposition. Change of the $\mathrm{C} / \mathrm{N}$ ratio of the faecal material with time was also significant and can be described by the regression equation $\mathrm{C} / \mathrm{N}$ $=46.60-0.77 \times$ (time of decomposition in days), $\mathrm{r}^{2}=$ $0.572, \mathrm{p}<0.005$ (Fig. 2).

\section{Amphipod growth experiment}

All Parhyalella sp. individuals in the control (C treatment, no food) died within $3 \mathrm{wk}$. Amphipods reared on the Rhizophora stylosa only diet also suffered high mortality and attained a cumulative mortality of about $93 \%$ by the end of the experiment. Malnutrition of these individuals was reflected by the small amount of faeces produced, although this was not quantitatively compared with the other treatments. In contrast, amphipods in the F and RF treatments only suffered some mortality during the initial week of the experiment, probably related to the stress experienced by the amphipods during handling and measurement The final cumulative mortality of these 2 groups was $\leq 20 \%$ at the conclusion of the experiment (Fig. 3a).

A second indication of the difference in performance of the amphipods in the various treatments was moulting frequency. While only $20 \%$ of the amphipods in the control treatment underwent moulting during the experiment, animals supplied with food in the $R, R F$ and $F$ treatments all exhibited higher frequencies of moulting even within the short experimental period. The cumulative moulting frequencies for the R, RF and F groups were 13,32 , and 26 , respectively, at the close of the experiment (Fig. 3b).
A comparison of the slopes of regression equations relating cumulative mortality and moulting frequency with. time suggests opposite trends demonstrated by the $F$ and $\mathrm{RF}$ treatments versus the $\mathrm{R}$ treatment and control (Table 2) Comparison of the regression slopes indicated significant treatment effect in both cumulative mortality and moulting frequency at $p<0.0005$. Multiple comparison of the regression slopes for cumulative mortality suggests the order $C>R>R F=F$ (Tukey's test, $p<0.001$ ) while the reverse was true for cumulative moulting frequency $(\mathrm{C}=\mathrm{R}<\mathrm{F}<\mathrm{RF}$; Tukey's test, $\mathrm{p}<0.001)$.

The difference in growth performance of the amphipods is not explicable by difference in ingestion rate. Apart from the control animals, which had a significantly lower gut fullness, values of the other 3 groups did not differ on the 3 sampling dates (Table 3) and were at $>65 \%$ full.

Assimilation efficiency of the amphipod for the 3 diets, estimated by comparing the concentration of various nutrients (carbon, nitrogen and organic matter) in the faecal material and the food given, suggests rather surprising values of the foods to the animal. Values of organic matter content of faecal material produced by amphipods in the F and RF treatments were higher than or very close to that of the crab faecal material (at $71.0,73.0$ and $70.7 \%$ respectively, Table 4 ), indicating effectively $0 \%$ or negative assimilation. Assimilation of $R$. stylosa leaf discs calculated according to the equation of Conover (1966) was, however, significantly more efficient at $46.4 \%$. There is therefore a large discrepancy in food value as indicated by the performance indicators (growth and mortality) and assimilation efficiency of organic matter.

Table 2. Coefficients of regression equations relating cumulative moulting frequency and cumulative mortality of amphipods in the various treatments with time. All equations are of the form Cumulative moults/mortality $=a \times$ (time in days) $+b$. Treatment had a significant effect on the regression slope $a$ in both cases (ANCOVA, at $\alpha=0.005$ ). Equations with the same number grouping have equal regression slopes (a) (Tukey's test, at $\alpha=0.001$ ). C: control, no food, R: Rhizophora stylosa leaf litter; F: faecal pellets; RF: leaf litter and faecal pellets

\begin{tabular}{|lccccc}
\hline \multicolumn{7}{l}{ Treatment $a$} & SE of $a$ & $r$ & $p$ & Croup \\
\hline \multicolumn{7}{l}{ Cumulative mortality } \\
C & 2.010 & 0.118 & 0.974 & $<0.0001$ & 1 \\
R & 1.250 & 0.046 & 0.986 & $<0.0001$ & 2 \\
F & 0.278 & 0.031 & 0.921 & $<0.0001$ & 3 \\
RF & 0.387 & 0.028 & 0.948 & $<0.0001$ & 3 \\
Cumulative no. of moults & & & \\
C & 0.833 & 0.088 & 0.963 & $<0.0001$ & 1 \\
R & 0.707 & 0.065 & 0.935 & $<0.0001$ & 1 \\
F & 1.210 & 0.034 & 0.992 & $<0.0001$ & 2 \\
RF & 1.560 & 0.031 & 0.996 & $<0.0001$ & 3 \\
\hline
\end{tabular}



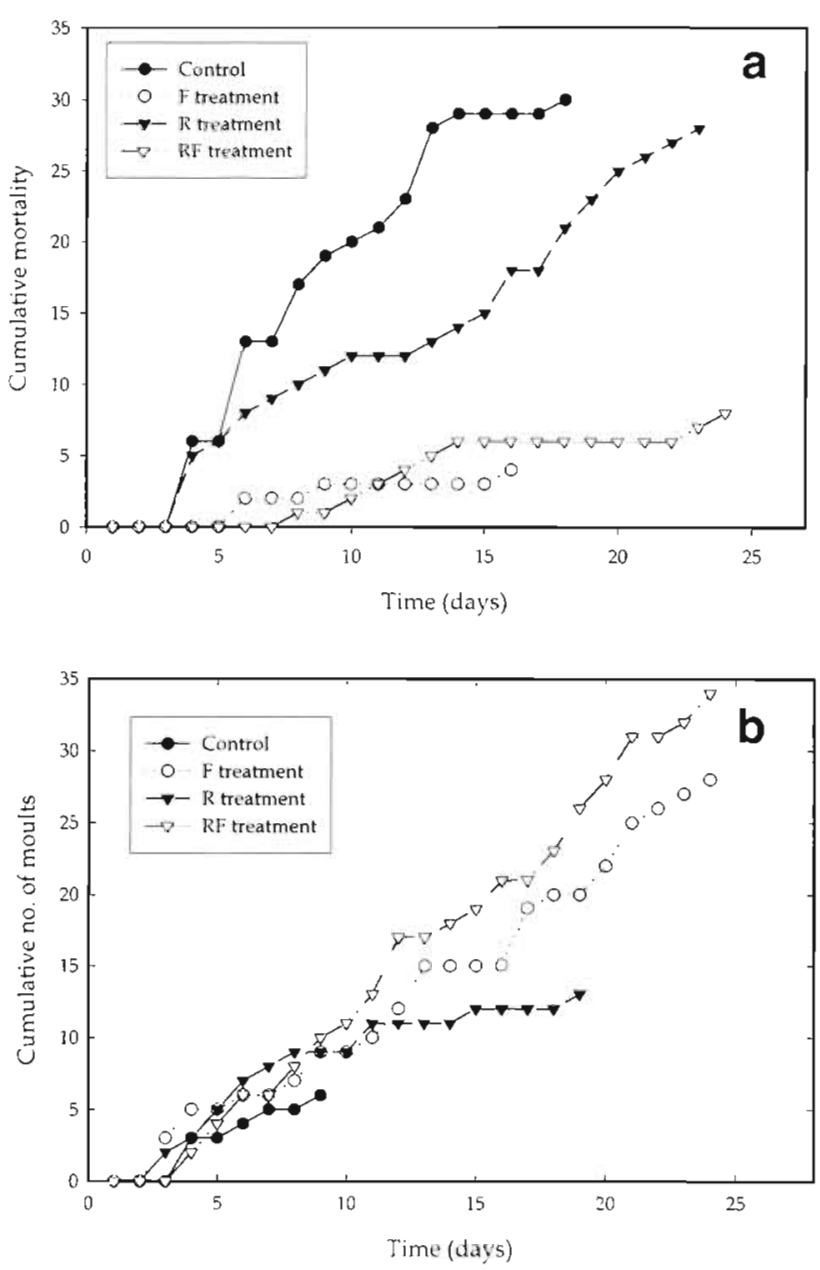

Fig. 3. Parhyalella sp. (a) Cumulative mortality of individuals and (b) cumulative number of moults in the 4 diet treatments of the growth experiment. Control: no food; F: faecal pellets; R: Rhizophora stylosa leat litter; RF: leaf litter and taecal pellets

This discrepancy may be explicable when the differences in $\mathrm{N}$ content of the food and faeces of the amphipods are considered (Table 4). The pattern of change for $\mathrm{N}$ before and after ingestion by the amphipod was exactly opposite that of organic matter. All faecal materials exhibited an increase in \% $\mathrm{N}$ over the original food source but the \% increase was highest for amphipods in the R treatment (faeces/Rhizophora leaf litter $=1.87$ ) and much lower in the RF and F treatments ( 1.42 and 1.36 respectively).

\section{DISCUSSION}

Although the role of sesarmine crabs in the turnover and fate of mangrove leaf litter in the Indo-Pacific has been implicated in many, and particlarly Old World, mangrove systems, their full significance as an agent in affecting mangrove energy flow is still to be established. Whereas the crabs can significantly reduce tidal export either through direct consumption or some form of caching, e.g. leaf burial (Robertson 1986), the actual evaluation of the importance of this process still requires information on 2 hitherto poorly explored issues: (1) the natural density of the crabs and (2) the fate of the leaf litter material ingested by the crabs

Density would provide crucial information as to the magnitude of an important multiplier for the extrapolation of feeding and/or defaecation rates measured in the laboratory to explain material fluxes in the natural habitat. Most past methods of crab density estimation were either too invasive or biased to provide reliable estimates of crab density in the mangrove. Attempts are being conducted to use remote control photography as a means to estimate crab density and size distribution with minimal disturbance (author's unpubl. data). A similar technique was used by Warren \& Underwood (1986) in their study of the impact of burrowing crabs on the topography of a New South Wales mangrove.

Most studies on crab consumption of mangrove litter stopped at estimating leaf ingestion rates and establishment of choice hierarchy. Thus, Robertson (1986) demonstrated the importance of the crab ingestion and caching pathway as an alternative to tidal export. Micheli (1993a, b) explored leaf choice hierarchy in relation to leaf chemistry. While earlier reports on leaf preference (e.g. Poovachiranon \& Tantichodok 1991. Lee 1993) suggest a great importance of nitrogen content (as expressed by the $\mathrm{C} / \mathrm{N}$ ratio) in the crabs' choice, this criterion does not seem to be applicable to Sesarma messa. This species consumes fresh senescent litter readily and leaf preference seems to be governed more by factors such as tannin concentration (Micheli 1993b). While Micheli actually measured faecal production, the data was not presented (see Micheli 1993a, p. 154) and was just used for the estimation of assimilation efficiency. The present report further supports that this pathway of crab consumption of mangrove leaf litter is potentially important by showing that large quantities of faecal material, still rich in nutrients and energy, are produced as a result of crab consumption of leaf litter; and that this faecal material could form the basis of a potential coprophagous food chain in the mangrove ecosystem.

One interesting finding of this study is the difference in carbon and nitrogen contents of the faecal material produced by crabs freshly collected from the mangrove forest and by crabs fed a pure diet of Rhizophora stylosa litter in the laboratory (C: 27.2 vs $34.4 \%$ and N: 1.44 vs $0.70 \%$ for field and $R$. stylosa diets respectively). This significantly higher $N$ content of faeces from the field diet suggests that the crabs probably 
Table 3. Parhyalella sp. Comparison of the degree of gut fuilness (in terms of $\%$ of the gut filled with food; mean \pm SD) of amphipods in the various treatments on 3 sampling dates using the Kruskal-Wallis non-parametric 1-way ANOVA. Multiple comparisons between the treatments were performed using the Dunn's test for Days 13 and 20. Dunn's test $\mathrm{RF}=\mathrm{R}=\mathrm{F}>\mathrm{C}$ at $\mathrm{p}<0.05$. Mann-Whitney $U$-test for Day 28 data

\begin{tabular}{|llccc|}
\hline Day & Treatment & \% fullness & K-W H & p \\
\hline 13 & Control & $31.2 \pm 26.9$ & 13.2 & 0.004 \\
& R & $72.3 \pm 35.4$ & & \\
& RF & $72.9 \pm 37.6$ & & \\
& F & $65.9 \pm 42.9$ & & \\
20 & R & $81.6 \pm 30.8$ & 2.07 & $0.354 \mathrm{~ns}$ \\
& RF & $68.7 \pm 38.2$ & & \\
& F & $79.1 \pm 32.9$ & & \\
& RF & $88.3 \pm 23.4$ & 660.0 & $0.355 \mathrm{~ns}$ \\
& F & $79.8 \pm 27.8$ & & \\
\hline
\end{tabular}

exploit a wide range of relatively $\mathrm{N}$-rich food sources in the mangrove, rather than just fresh mangrove leaf litter, although this latter food source seems to be the 'staple diet' of the crabs. Sesarmine crabs do spend a lot of time picking from the mud surface (e.g. Micheli 1993b, Kwok 1995), probably tapping the microbial resources available from the substrate. The natural bacterial productivity in surface mangrove sediments can be considerable, averaged at $1.6 \mathrm{~g} \mathrm{C} \mathrm{m}^{-2} \mathrm{~d}^{-1}$ in the Australian wet tropics (Alongi 1988). Given the rapid $N$ enrichment (presumably through microbial colonisation) of the crab faecal material after deposition as recorded by this study, this high bacterial productivity could itself be in turn supported by the release of mangrove derived organic matter in the form of faecal input from the crabs onto the sediment surface.

Emmerson \& McGwynne (1992) estimated that a total of $75 \mathrm{t}$ of frass or faecal material could be produced through crab consumption in a South African mangrove. The consumption and defaecation rates reported by these authors and Micheli (1993b) are scaled to unit fresh weight of the crabs and are there-

Table 4. Parhyalella sp. Chemical characteristics of the faecal material produced by individuals in the 3 dietary treatments $\mathrm{C}$ and $\mathrm{N}$ values are mean $\pm \mathrm{SD}$. Due to the small amount of samples avalable, only duplicate measurements were made for OM (organic matter) and the mean is shown here. All values are based on dry weights. nd: no data

\begin{tabular}{|lccccc|}
\hline Treatment, & $\% \mathrm{C}$ & $\% \mathrm{~N}$ & $\mathrm{C} / \mathrm{N}$ & $\% \mathrm{OM}$ & $\%$ tannin \\
\hline $\mathrm{R}$ & $41.0 \pm 0.9$ & $1.04 \pm 0.05$ & 39.4 & 71.7 & nd \\
$\mathrm{RF}$ & $40.9 \pm 0.9$ & $1.00 \pm 0.12$ & 41.0 & 73.0 & 2.00 \\
$\mathrm{~F}$ & $39.1 \pm 0.2$ & $0.95 \pm 0.51$ & 41.2 & 71.0 & 1.94 \\
\hline
\end{tabular}

fore not directly comparable with those obtained in the present study. Using a 3.56:1 fresh wt:dry wt ratio for the sesarmines (as recorded for Sesarma messa in this study), the faecal production values obtained for $S$. messa in the present study seem to be significantly higher than those of Emmerson \& McGwynne (1992) for $S$. meinerti (2.02 to $1.40 \mathrm{mg}$ dry $\mathrm{wt} \mathrm{g}^{-1}$ crab wet $w \mathrm{t}$ $\mathrm{d}^{-1}$ ). Robertson et al. (1992) estimated that $462 \mathrm{~kg} \mathrm{C}$ ha ${ }^{-1} \mathrm{yr}^{-1}$ of crab faecal material may be produced from the consumption of $700 \mathrm{~kg} \mathrm{Cha-1} \mathrm{yr}^{-1}$ of mangrove litter fall (faeces to leaf ratio at 0.66 , assuming identical carbon contents for the 2 materials). These figures are similar to those recorded in the present study. Assuming a field density of 6 ind. $\mathrm{m}^{-2}$ for $S$. messa (Micheli 1993a) and extrapolating from the values obtained in the present study, the faceal material produced by this crab amounts to about $0.359 \mathrm{~g} \mathrm{~m}^{-2} \mathrm{~d}^{-1}$, which is equivalent to about $24 \%$ of the leaf litter fall of a typical $R h i-$ zophora forest in northern Australia $\left(556 \mathrm{~g} \mathrm{~m}^{-2} \mathrm{yr}^{-1}\right.$; Bunt 1982, Robertson 1986). A quarter of the mangrove leaf litter production could therefore be made available to a potential coprophagous food chain by invertebrates both within and close to the mangroves. Such an estimate is, however, based on laboratory values for leaf consumption and defaecation rates and has to be confirmed by further, preferably field-based, measurements.

The results of the amphipod growth experiment strongly demonstrate the potential significance of this linkage. The crabs, through their consumption of mangrove leaf litter, could provide the basis for a potential coprophagous food chain involving small invertebrates such as Parhyalella sp. This aspect of the trophic importance of the mangrove sesarmines has been neglected in the past. Food chain relationships involving small macroinvertebrates in the mangrove are poorly known. Poovachiranon et al. (1986) reported upon grazing by the amphipod Parhyale hawaiensis of Rhizophora stylosa litter accumulated in the high intertidal near the study site of the present study. While $P$. hawaiensis and Parhyalella sp. are probably both capable of surviving on a diet of relatively fresh or decaying mangrove litter, the striking differences in growth performance of the amphipods between the $R$ and the $F$ and RF treatments in this study suggest that crab-processed litter, e.g. in the form of faecal material, could represent an important component of the natural diet of these small invertebrates. The general lack of difference in performance between the RF and F groups but a significant difference from the R group suggests that crab faecal material was the more profitable food source to the amphipods. While the amphipod is only locally abundant in the accumulated detritus, it can be expected that other, pelagic as well as benthic, invertebrates (e.g. copepods and oligo- 
chaetes) in the immediate vicinity of the mangroves could also benefit from this coprophagous food chain. Under natural tidal inundation, the crab faecal material will probably disintegrate in a relatively short time and be transported by tidal water. The faecal material, therefore, may exist as an alternative form of matter exported from the mangroves, in this case first processed in situ by the abundant sesarmine crabs within the forest itself.

The assimilation efficiencies of the amphipods feeding on their natural or experimental food items are somewhat intriguing. As mentioned in 'Results', there are discrepancies between conclusions that can be drawn from the results of the growth experiment and from the calculated assimilation efficiencies about the value of the 3 food treatments. While the difference in performance of amphipods in the various treatments seems apparent, the question remains as to why assimilation efficiencies calculated using the method of Conover (1966) failed to give a congruent indication of food value. The method of Conover (1966) assumes that only the organic fraction of the food was digested. Estimation of change in the ash-free dry wt:dry wt ratio is usually by the loss-on-ignition method (as in Conover 1966 and in this study), which is mainly responsive to the carbon content of the food. These practices may have produced the anomaly, as indicated by negative assimilation of the food items (as in the F and RF treatments), which apparently produced significantly better growth and survival performance of the test animals. As has been demonstrated by the early works of Newell (1965) and subsequent works on coprophagy, coprophagous animals usually tap much more heavily into the $\mathrm{N}$ than into the $\mathrm{C}$ content of their food. An assimilation efficiency value calculated based simply on the change in \% organic matter, which is overwhelmingly dominated by the $\mathrm{C}$ rather than the $\mathrm{N}$ content, through digestion probably cannot indicate food quality satisfactorily in the case of coprophagous food chains. Although the change in $\% \mathrm{~N}$ between food and faeces of the amphipod seems to be more congruent with the results of the growth experiment, it is still interesting, if not disturbing, to note that there is an increase in $\mathrm{N}$ level after digestion in all cases. Previous studies on deposit-feeders suggest that microbial colonisation of the partially digested material can take place even before the food is completely digested, e.g. strains of Aeromonas sp. and Vibrio alginolyticus multiplied by between 2 and 3 orders of magnitude in abundance between the hind gut and rectum of Arenicola vagabunda (Plante et al. 1989). Similar proliferation of bacteria on the egested faecal material from Parhyellela sp. and Sesarma messa could explain the modest increase in $\mathrm{N}$ content of their faeces over that of their diet. Alternative means such as measurement of respiration of the faecal material may help provide more insight into the dynamics of microbial flora growing on the organic matter being recycled through macro-detritivore consumption and coprophagous invertebrates.

The increase in the nitrogen content of the crab faecal material with time, as demonstrated by the chemical changes following decomposition, is probably a result of colonisation by microbes. Direct measurement of microbe abundance associated with the faecal material will help confirm this. The nitrogen content of the faecal material increased significantly (to $1.5 \%$ ) after about 2 wk of decomposition. This increase was paralleled by a decrease in the carbon content, resulting in an overall decreasing trend for the $\mathrm{C} / \mathrm{N}$ ratio with time. The low $\mathrm{C} / \mathrm{N}$ ratio of the faecal material compared favourably with the leaf litter of Rhizophora stylosa, the other major potential food source available in the system, further providing support for the significance of sesarmine crabs in the trophic ecology of northeastern Australian mangroves.

Acknowledgements. This work was conducted while the author was visiting the Australian Institute of Marine Science. l am grateful to the mangrove research group of AIMS for the provision of laboratory space and facilities for the study. The hospitality and logistical assistance of various scientists and personnel at AIMS have been instrumental to the completion of the work. In particular, I thank Drs Barry Clough, Norm Duke and Janet Ley for their help in administrative arrangements. Paul Dixon, Otto Dalhause, Mick Vaugh and Ernie Taylor provided unlimited assistance in various ways. Dr Graham Edgar kindly identified Parhyalella at the cost of a beer. Dr Dan Alongi and Professor Alistar Robertson read and provided constructive criticisms on drafts of the manuscript.

\section{LITERATURE CITED}

Abele LG (1992) A review of the grapsid crab genus Sesarma (Crustacea: Decapoda: Grapsidae) in America, with the description of a new genus. Smithson Contrib Zool 527. $1-60$

Allen SE (1989) Chemical analysis of ecological materials. Blackwell Scientific Publications, Oxford

Alongi DM (1988) Bacterial productivity and microbial biomass in tropical mangrove sediments. Microb Ecol 15: $59-79$

Bertness MD (1985) Fiddler crab regulation of Spartina alterniflora production on a New England salt marsh. Ecology 66:1042-1055

Bunt JS (1982) Studies of mangrove litter fall in tropical Australia. In: Clough B (ed) Mangrove ecosystems in Australia. Australian National University Press, Canberra, p 223-237

Conover RJ (1966) Assimlation of organic matter by zooplankton. Limnol Oceanogr 11:338-354

Davie PJF (1994) Variations in diversity of mangrove crabs in tropical Australia. Mem Queensl Mus 36:55-58

Emmerson WD, MCGwynne LE (1992) Feeding and assimilation of mangrove leaves by the crab Sesarma meinerti de Man in relation to leaf-litter production in Mgazana, a 
warm-temperate southern African mangrove swamp. J Exp Mar Biol. Ecol 157:41-53

Giddens RL, Lucas JS, Neilson MJ, Richards GN (1986) Feeding ecology of the mangrove crab Neosarmatium smithi (Crustacea: Decapoda: Sesarmidae). Mar Ecol Prog Ser 33: $147-155$

Jones DA (1984) Crabs of the mangal ecosystem. In: Por FD, Dor I (eds) Hydrobiology of the mangal. Dr. W Junk Publishers, The Hague, p 89-109

Kwok PW (1995) The ecology of two sesarmine crabs, Perisesarma bidens (De Haan) and Parasesarma plicata (Latrielle) at the Mai Po Marshes Nature Reserve, Hong Kong. PhD thesis, The University of Hong Kong

Kwok PW, Lee SY (1995) The growth performances of two sesarmine crabs Perisesarma bidens and Parasesarma plicata under different diets. Hydrobiologia 295:141-148

Lee SY (1989) The importance of Sesarminae crabs Chiromanthes spp. and inundation frequency on mangrove [Kandelia candel (L.) Druce] leaf litter turnover in a Hong Kong tidal shrimp pond. J Exp Mar Biol Ecol 131:23-43

Lee SY (1993) Leaf choice of the sesarmine crabs, Chiromanthes bidens and $C$. maipoensis, in a Hong Kong mangal. In: Morton B (ed) The marine biology of the South China Sea. Hong Kong University Press, Hong Kong, p 597-603

Macnae W (1968) A general account of the fauna and flora of mangrove swamps and forests in the Indo-West-Pacific region. Adv Mar Biol 6:73-270

McIvor CC, Smith TJ III (1995) Difference in the crab fauna of mangrove areas at a southwestern Florida and a northeastern Australian location: implications for leaf litter processing. Estuaries 18:591-597

Micheli F (1993a) Effect of mangrove litter species and availability on survival, moulting and reproduction of the mangrove crab Sesarma messa. J Exp Mar Biol Ecol 171. $149-163$

Micheli F (1993b) Feeding ecology of mangrove crabs in North Eastern Australia: mangrove litter consumption by Sesarma messa and Sesarma smithii. J Exp Mar Biol Ecol $1.71: 164-186$

Newell RC (1965) The role of detritus in the nutrition of two marine deposit feeders, the prosobranch Hydrobia ulvae and the bivalve Macoma balthica. Proc Zool Soc Lond $144: 25-45$

Plante CJ, Jumars PA, Baross JA (1989) Rapid bacterial growth in the hind gut of a marine deposit feeder. Microb Ecol 18:29-44

Poovachiranon S, Boto KG, Duke $N$ \{1986\} Food preference studies and ingestion rate measurements of the mangrove amphipod Parhyale hawaiensis (Dana). J Exp Mar Biol Ecol 98:129-140

Edstorial responsibility Otto Kinne (Editor).

Oldendorf/Luhe, Germany
Poovachiranon S, Tantichodok P (1991) The role of sesarmıd crabs in the mineralisation of leaf litter of Rhizophora apiculata in a mangrove, southern Thailand. Phuk Mar Biol Cent Res Bull 56:63-74

Robertson AI (1986) Leaf-burying crabs: therr influence on energy flow and export from mixed mangrove forests (Rhizophora spp.) in northeastern Australia. J Exp Mar Biol Ecol 102:237-248

Robertson AI (1991) Plant-animal interactions and the structure and function of mangrove forest ecosystems. Aust $\mathrm{J}$ Ecol 16:433-4.41

Robertson AI, Alongi DM, Boto KG (1992) Food chains and carbon fluxes. In: Robertson Al, Alongi DM (eds) Tropical mangrove ecosystems. American Geophysical Unon, New York, p 293-326

Robertson Al, Daniel PA (1989) The influence of crabs on litter processing in high intertidal mangrove forests in tropical Australia. Oecologia 78:191-198

Smith TJ III (1987a) Seed predation in relation to the dominance and distribution in mangrove forests. Ecology 68: $266-273$

Smith TJ III (1987b) Effects of seed predators and light level on the distribution of Avicennia marine (Forsk.) Vierh. in tropical tidal forests. Estuar Coast Shelf Sci 25:43-51

Smith TJ III (1988) The influence of seed predators on structure and succession in tropical tidal forests. Proc Ecol Soc Aust 15:203-211

Smith TJ III, Boto KG, Frusher SD, Giddens RL (1991) Keystone species and mangrove forest dynamics: the influence of burrowing by crabs on soil nutrient status and forest productivity. Estuar Coast Shelf Sci 33:419-432

Smith TJ III, Chan HT, MCIvor CC, Roblee MB (1989) Comparisons of seed predation in tropical tidal forests from three continents. Ecology 70:146-151

Steinke TD, Rajh A, Holland AJ (1993) The feeding behaviour of the red mangrove crab Sesarma meinerti de Man, 1887 (Crustacea: Decapoda: Grapsidae) and its effect on the degradation of mangrove leaf litter. S Afr J Mar Sci 13 $151-160$

Tan CGS, Ng PKL (1994) An annotated checklist of mangrove brachyuran crabs from Malaysia and Singapore. Hydrobiologia 285:75-84

Taylor DI, Allanson BR (1993) Impacts of dense crab populations on carbon changes across the surface of a salt marsh. Mar Ecol Prog Ser 101:119-129

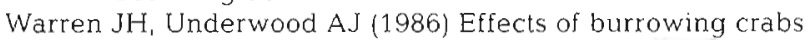
on the topography of mangrove swamps in New South Wales. J Exp Mar Biol Ecol 102:223-225

Zar JH (1984) Biostatistical analysis. Prentice Hall, Englewood Cliffs, NJ

Submitted: January 20, 1997; Accepted: August 12, 1997

Proofs received from author(s): November 10, 1997 